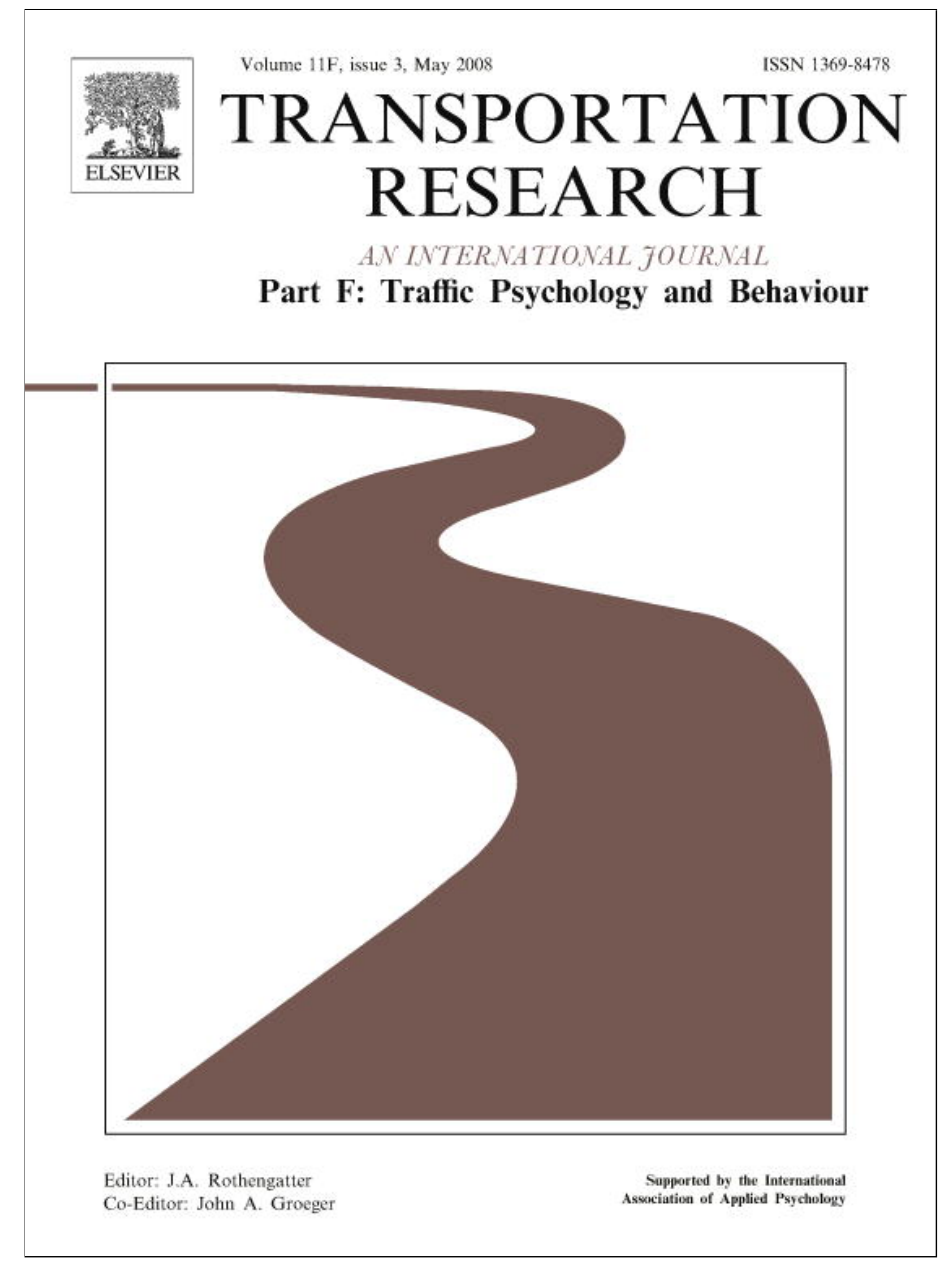

This article appeared in a journal published by Elsevier. The attached copy is furnished to the author for internal non-commercial research and education use, including for instruction at the authors institution and sharing with colleagues.

Other uses, including reproduction and distribution, or selling or licensing copies, or posting to personal, institutional or third party websites are prohibited.

In most cases authors are permitted to post their version of the article (e.g. in Word or Tex form) to their personal website or institutional repository. Authors requiring further information regarding Elsevier's archiving and manuscript policies are encouraged to visit:

http://www.elsevier.com/copyright 


\title{
Measuring cognitive determinants of speeding: An application of the theory of planned behaviour
}

\author{
Helmut Paris ${ }^{a}$, Stephan Van den Broucke ${ }^{b, *}$ \\ ${ }^{a}$ Department of Mobility and Safety, Ministry of the Flemish Community, Belgium \\ ${ }^{\mathrm{b}}$ Research Group for Health Psychology, Katholieke Universiteit Leuven, Tiensestraat 102, 3000 Leuven, Belgium
}

Received 7 March 2007; received in revised form 6 September 2007; accepted 6 September 2007

\begin{abstract}
This article describes the development and validation of a self-report questionnaire to measure the determinants of speeding behaviour in road traffic, based on the theory of planned behaviour. A provisional questionnaire measuring self-reported speeding behaviour as well as its determinants as predicted by the TPB model (attitudes towards speeding and towards respecting speed limits, social norms, perceived behavioural control, and intentions) was completed by 116 drivers. Separate principal component analyses on the items measuring attitudes, social norms and perceived control resulted in two component solutions, explaining between $46.5 \%$ and $57.5 \%$ of the variance, for each determinant. After Promax rotation, these solutions were used to construct eight scales comprising 2-7 items each, measuring negative and positive attitude towards speeding, negative and positive attitude towards respecting speed limits, explicit and implicit social norm, and perceived internal and external control, respectively. Internal consistencies ranged from .51 to .82 . Scale scores accounted for a significant proportion of the variance in intention and self-reported behaviour. Intentions were most strongly predicted by explicit social norms and negative attitude towards respecting speed limits. Self-reported speeding was predicted by intention and perceived internal control. In contrast, actual speeding behaviour was not significantly predicted by intentions and perceived control. The study demonstrates the validity of the theory of planned behaviour to predict self-reported speeding behaviour and provides a valid and reliable measure of the cognitive concepts featured in this model, but suggests that actual speeding behaviour can only partially be predicted from these concepts.
\end{abstract}

(c) 2007 Elsevier Ltd. All rights reserved.

Keywords: Theory of planned behaviour; Road safety; Speeding; Determinants; Measurement

\section{Introduction}

Traffic accidents are a prominent cause of injuries and premature mortality worldwide, especially among children and young people. According to estimations of the World Health Organization, 1.171.000 deaths and many more cases of disability are caused by road traffic accidents annually (WHO, 2000). While in

\footnotetext{
${ }^{*}$ Corresponding author. Tel.: +35 2430137897; fax: +35 2430130359.

E-mail address: stephan.vandenbroucke@psy.kuleuven.be (S.V.d. Broucke).
} 
1998 road traffic injuries were the ninth most important problem in the global burden of disease, they are expected to take up the third place in the ranking of disease burden by the year 2020 (Peden, Krug, \& Mohan, 2001). Even in countries with a relatively high level of traffic safety, road traffic injuries represent a major public health threat. In the 15 EU Member States before the enlargement of 2004, approximately 40.000 deaths and 1.7 million injuries were attributed to traffic accidents per year. This means that in a lifetime, one of every three Europeans will get injured in traffic (European Commission, 2003).

In addition to driving under the influence of alcohol and not using seat belts, driving at an inappropriate speed is considered to be one of the most important factors causing death and injuries in traffic accidents (European Commission, 2003). High speed not only reduces the control of the vehicle, but also increases the fatality risk of a traffic accident (Garvill, Marell, \& Westin, 2003). In order to address these consequences, policy makers are increasingly taking measures to reduce speeding. Most of these measures involve environmental or legislative interventions, such as changing the road infrastructure (e.g., speed bumps, road constrictions and roundabouts), increasing the cost of speeding (e.g., higher fines for speeding violation), or increasing the probability of a fine (e.g., installing speed cameras). These measures have not been without success: although the evidence is not always conclusive and better controlled studies are needed, systematic reviews suggest that speed cameras and traffic calming infrastructure have the potential to reduce road traffic injuries (Aeron-Thomas \& Hess, 2005; Bunn et al., 2003; De Brabander, Nuyts, \& Vereeck, 2005; Pilkington \& Kinra, 2005). However, as these measures primarily induce behaviour change by enforcing it externally, they have no effect on the intrinsic motivation of the drivers to adjust their speed. As a consequence, the positive effects are often limited in time and space. Reviewing traffic enforcement in Europe, Mäkinen et al. (2003) concluded that studies of the enforcement impact give a fairly uniform picture that compliance is very high in the immediate vicinity of the surveillance site, but that speed increases as soon as the site has been passed. Thus, sustained effects of speed reduction are not conceivable without taking into account the motivational aspects and processes of the drivers as well (Hatakka, Keskinen, Gregersen, Glad, \& Hernetkoski, 2002; Harloff, 1994; Victoir, Eertmans, Van den Bergh, \& Van den Broucke, 2005).

To understand these factors, use can be made of preventive behaviour change models (De Pelsmacker \& Janssens, 2007; Gielen \& Sleet, 2003; Trifiletti, Gielen, Sleet, \& Hopkins, 2005). These models identify the social cognitive factors that predict preventive behaviour change and that may serve as the focus of interventions. One of the most influential of these models is the theory of planned behaviour (Ajzen, 1991; Ajzen \& Madden, 1986). According to this model, volitional behaviour is to a large extent determined by the intention to perform that behaviour. This intention is in itself a function of three social cognitive variables: attitudes towards the behaviour, perceived social norms with regard to the behaviour, and perceived behavioural control. An attitude can be defined as the positive or negative evaluation of the expected outcomes of the behaviour, both in terms of instrumental outcomes (e.g., needing less time to get to one's destination) and affective outcomes (e.g., the pleasure of driving fast). Social norms refer to the perceived social influence to engage in the behaviour of interest, and are derived from the behaviour and/or direct feedback of significant others (i.e., implicit and explicit norm, respectively). The extent to which these norms influence behaviour depends on the motivation to comply with them. Perceived behavioural control is the degree to which an individual believes that the behaviour is under his or her control. Intention is thus considered as a mediating factor in the association between attitude, subjective norm and perceived behavioural control on the one hand, and behaviour on the other hand. However, since the performance of behaviour can be impeded by factors that are beyond volitional control, perceived behavioural control can also predict behaviour directly.

Applied to traffic safety, the theory would hold that drivers who see little practical or affective benefits to respecting the speed limits will be more inclined to drive fast. Further, driving speed is also influenced by the perceived norms with regard to speeding as propagated by friends, spouses, and other significant others. Compared to other risk behaviours, such as drink driving, speeding is generally less stigmatized, which suggests that social norms legitimize it as an "acceptable" behaviour (Stead, Tagg, MacKintosh, \& Eadie, 2005). Finally, drivers may or may not believe that they possess the skills to drive fast, or be convinced that speeding is (or is not) under their personal control. These considerations result in an intention to drive at adjusted or maladjusted speed, which is the most proximal determinant of the actual performance. 
The theory of planned behaviour has been applied to a broad range of preventive behaviours, including smoking, physical activity, food choice and alcohol consumption. Meta-analytic reviews of the TPB have supported its ability to predict these behaviours (Ajzen \& Madden, 1986; Godin \& Kok, 1996). Armitage and Conner (2001) reported that attitude, subjective norm and perceived behavioural control in combination accounted for a frequency weighted average of $39 \%$ of the variance in intention across 154 applications, and that intentions and perceived behavioural control explained $27 \%$ of the variance in behaviour across 63 applications. In traffic research, the TPB has been used to explain pedestrian's and drivers' intentions to violate traffic rules (Evans \& Norman, 1998; Moyano Diaz, 2002; Parker, Manstead, Stradling, Reason, \& Baxter, 1992), driver's intentions to drink and drive (Aberg, 1993; Marcil, Bergeron, \& Audet, 2001), use of safety belts (Budd, North, \& Spencer, 1984; Thuen \& Rise, 1994; Wittenbracker, Gibbs, \& Kahle, 1983) and the use of child restraint devices (Gielen, Eriksen, Daltroy, \& Rost, 1984). With regard to speeding, Parker et al. (1992) found that approximately $50 \%$ of the variance of an individual's intention to keep to speed limits is determined by the combination of attitudes, subjective norms and perceived behavioural control. Similarly, Godin and Kok (1996) confirmed that the constructs of the TPB accounted for 23-67\% of the variability in intended driving behaviour, including speeding.

In addition, some authors have used constructs derived from the TPB or modified versions of the model to predict traffic behaviour. For example, Elliott, Armitage, and Baughan (2003) reported that constructs included in the TPB were associated with self-reported compliance with speed limits. In a similar vein, Haglund and Aberg (2000) found that the external pressure to keep up with other drivers was a significant predictor of speeding intentions. Armitage and Conner (1999) argued that perceived behavioural control and self-efficacy are in fact different constructs, and demonstrated that both contribute to the prediction of intentions to drink and drive (Armitage, Norman, \& Conner, 2002). Intentions to speed or commit driving violations could also be predicted more strongly by the addition of anticipated regret, moral norm, personal identity and habit formation to the original TPB framework (De Pelsmacker \& Janssens, 2007; Newnam, Watson, \& Murray, 2004; Parker, Manstead, \& Stradling, 1995).

Despite its potential to inform about behavioural determinants, the TPB has only sparingly been used to design and evaluate traffic safety interventions. The few examples of interventions that have been based on the TPB include the modification of beliefs and attitudes towards speeding (Parker, Stradling, \& Manstead, 1996), educational programmes to increase the use of safety helmets among young cyclists in the UK (Quine, Rutter, \& Arnold, 2001), interventions to promote the use of children's safety seats (Gielen et al., 1984), and a mass media campaign to reduce speeding, where the TPB was used as a framework for evaluation (Stead et al., 2005). However, most of these studies have used ad hoc measures to operationalise the concepts of the TPB, providing little proof of their conceptual validity. On the other hand, those studies that did involve more psychometrically validated operationalisations usually applied situationally specific measures requiring elaborate methods for data collection. For example, Stead et al. (2005) used 20-40 minute face to face at home interviews administered by professional market researchers to measure TPB-based determinants of speeding, reporting adequate levels of internal consistency for all measures. The elaborate nature of this approach makes it difficult to be used in other studies.

Moreover, the existing operationalisations of the TPB dimensions are only validated on self-report data regarding traffic behaviour. Although there is a correlation between self-reported and observed behaviour in traffic, this correlation is only moderate. Haglund and Aberg (2000) reported a path coefficient of .44 between self-reported and observed driving speed. While the TPB assumes that behaviour is mostly under conscious and rational control (Godin \& Kok, 1996), traffic behaviour to a large extent involves routines and "scripts" which are mostly subconscious (Victoir et al., 2005). So while a driver's intention to respect the speed limits is a determinant of his or her actual speed behaviour and can partially be predicted by the TPB, its impact on actual behaviour is reduced by other factors. This makes it more likely for the dimensions of the TPB to be associated with measures of self-rated behaviour than with actual behaviour (Armitage \& Conner, 1999; Armitage \& Conner, 2001; Rothengatter, 2002). Therefore, instruments for informing about behaviour change efforts should not only be validated against self-reports, but also against objective measures of behaviour.

The present study was aimed to develop and validate a relatively short and user friendly self report questionnaire measuring the determinants of speeding behaviour based on the TPB, using actual speeding behaviour in addition to self reported behaviour as a criterium measure. 


\section{Method}

\subsection{Instrument}

A questionnaire was developed to measure speeding in traffic as well as the determinants of this behaviour as proposed by the theory of planned behaviour. The questionnaire was drafted in Dutch. For each of the dimensions of this model (i.e., attitudes, social norms, perceived behavioural control, and intentions), 6 to 12 items were formulated in the form of statements to be answered on a 5 point Likert scale $(1=$ strongly disagree, $2=$ disagree, $3=$ agree nor disagree, $4=$ agree, $5=$ strongly agree). Attitude items referred both to fast driving and to respecting the speed limits, and were operationalised as expected outcomes without specifically asking for the evaluation of the outcome, since the latter was usually obvious. Social norms were operationalised as perceived implicit (normative and personal) or explicit (subjective) norms, without referring to the motivation to comply, as multiplicative composites are considered problematic (Van den Putte \& Hoogstraten, 1997; Victoir et al., 2005). To prevent tendencies of social conformation, some of the items were formulated in a negative way. Intention and self-reported behaviour were measured with 1 item each. Although the use of single items to measure intentions and behavior prohibits the possibility to establish the reliability of the intention scales, direct measures of intention are more parsimonious, and are often used in tests of the TPB (Godin \& Kok, 1996).

Following a face validity check by experts external to the study, a 42 item questionnaire was obtained of which 12 items were intended measure the attitude towards fast driving (e.g., "Driving fast makes you feel independent and free"; "Driving fast makes you save time."); 12 items measured the attitude towards respecting the speed limits (e.g., "Respecting the maximum speed limit reduces the chance to get involved in an accident." "Respecting the maximum speed limit makes you drive in a more relaxed way"; 10 items measured social norms (e.g. "My partner thinks that I should respect the speed limits" [subjective norm], "Most car drivers in Flanders do not respect the speed limits." [normative norm]; "Occasionally driving faster than the speed limit is acceptable" [personal norm]); 6 items measured perceived behavioural control (e.g., "If I choose to respect the maximum speed limit, I can do it"; "I have often tried to drive slower but I can't"); 1 item measured intention ("From now on, I intend to keep to the speed limits") and 1 item measured self-reported behaviour ("Usually I keep to speed limits"). A number of questions were added asking for personal and demographic characteristics, professional activity, driving experience and driving habits.

\subsection{Participants}

The questionnaires were sent anonymously by post to a convenience sample of 184 Flemish civil servants, with a pre-stamped envelope for reply. 116 completed questionnaires were returned, giving a response rate of $63 \%$. The sample included 82 males $(70.7 \%)$ and 34 females $(29.3 \%)$, with a mean age of 38.6 years, and a relatively high level of education (51.7\% with a university degree). They represented a variety of different functions, with $25.9 \%$ of the participants occupying a managing position, and $64.7 \%$ an executive function. While only $7.8 \%$ of the participants used their car in relation to their job, e.g. as a chauffeur, the majority were experienced drivers: $51 \%$ had a driving license for more than 15 years, $42 \%$ between 5 and 15 years, and only $3.4 \%$ for less than 5 years. One out of four participants (25\%) drove more than $30,000 \mathrm{~km}$ per year, $45 \%$ between 10,000 and $30,000 \mathrm{~km}$ per year, and $28 \%$ less than 10.000 kilometer per year. The majority of the participants $(69 \%)$ had already been involved in a traffic accident once.

For a subgroup of 55 participants, the actual driving behavior was monitored during a 3 week period following the completion of the questionnaire, as part of another study. This subgroup was selected from the total group on the basis of accessibility and annual distance driven (i.e., they used their cars to commute to work so as to facilitate the installation of the monitoring equipment and make sure that they attained sufficient mileage during the monitoring period). They did not differ significantly from the other participants on any of the demographic variables. The behavioural monitoring was done by means of an on-board CPU connected to a central unit through GPS/GPRS and linked to a digital speed map of the region. This monitoring enabled the calculation of the drivers' average speed, the number of speed 
violations (i.e. exceeding the maximum speed at a given location), and the duration of the speeding episode. The participants were informed that their speed would be monitored after an initiation period during which they could become used to the equipment in their vehicle, but were not told when the actual monitoring began.

\subsection{Statistical analyses}

The participants' responses on the provisional questionnaire were entered into an SPSS data file, after which the distribution of the responses was inspected to eliminate items with a low discriminative power (i.e., $95 \%$ or more of the answers in the same category or a standard deviation lower than .75). Principal Component Analysis (PCA) was used to examine the underlying structure of the scales. In a first analysis, all items except intention and self-reported behaviour were included in a single PCA, using the eigenvalue and scree plot criteria to determine the number of components to be extracted and VARIMAX rotation to yield maximum discrimination between the scales. As this analysis did not produce an interpretable result, a separate PCA with PROMAX rotation was performed on the items of each determinant (i.e., the two attitude scales, social norm and perceived behavioural control) to identify subdimensions within each conceptually derived scale. Subscales were constructed on the basis of the resulting component structure, by assigning items to a scale for which they attained the highest component loading. Items with a component loading lower than .40 on any scale were eliminated, as were items with a small difference in factor loading on any two components. Because of the relatively small sample size, scale scores were calculated on the basis of average rather than factor scores. The internal consistency of the scales obtained through the PCA was tested by means of the Cronbach alpha statistic, and Pearson correlations were computed to check the interrelatedness between the scales.

To assess predictive validity, multiple regression analyses were applied to evaluate whether the scales representing attitude, social norm and perceived behavioural control could predict the intention to respect speed limits, and if intention in combination with perceived behavioral control could predict self-reported behavior, as stated by the TPB. For the respondents whose driving behaviour had been monitored, multiple regressions were used to assess the prediction of average speed, number of speed violations and average duration of the violations from the intention and perceived behavioural control scales, as well as directly from the attitude and social norm scales. Finally, the discriminative power of the questionnaire was investigated by looking at the gender disparity in the determinants of speeding behaviour using multivariate analysis of variance (MANOVA), with gender as the independent and the scores on the attitude, social norm and perceived behavioural control scales as dependent variables.

\section{Results}

\subsection{Item analysis}

The distribution of the responses on each item indicated that none of the items was skewed, and that all of them showed sufficient variation across the response categories (i.e., less than $95 \%$ of responses on a single category or SD $<.75$ ). Consequently, no item had to be discarded for low discriminative power. However, one of the items assessing the social norm with regard to speeding behaviour ("My children find that I have to keep to speed limits") had to be removed because it was unanswered by a high number of participants.

\subsection{Construct validity}

A Principal Component Analysis on all 39 items measuring the determinants of behaviour produced 12 components with an eigenvalue higher than one, accounting for $76.66 \%$ of the total variance. An inspection of the scree plot revealed that the last four components did not add much variance to the solution. An 8 component factors solution accounted for $65.18 \%$ of the total variance, but after Varimax rotation this solution did not produce an interpretable result. 
Separate PCA's for the items measuring attitude towards driving fast, attitude towards respecting speed limits, subjective social norm and perceived behavioural control gave the following results.

\subsubsection{Attitude towards fast driving}

A principal component analysis on the 12 items measuring the attitudes towards fast driving resulted in a 4-component solution accounting for $66.47 \%$ of the total variance when the eigenvalue $>1$ criterion was applied, and in a solution with two components accounting for $46.51 \%$ of the variance using the scree plot criterion. Preference was given to the latter solution for ease of interpretation. An oblique Promax-rotation resulted in 7 items loading on the first component, explaining $27.38 \%$ of the total variance, and 5 on the second component, explaining $24.78 \%$. Based on the item content, the components could be interpreted as, respectively, positive and negative attitude towards driving fast. The correlation between the two components was -.342 .

\subsubsection{Attitude towards respecting speed limits}

A principal component analysis on the 12 items measuring this construct produced a 4-component solution explaining $63.59 \%$ of the variance when using the eigenvalue $>1$ criterion, and a three component solution when using the scree plot. The last component, however, contained only 2 items which did not have much in common. After discarding these two items, a 2 component solution was obtained which accounted for $50.63 \%$ of the total variance. After a Promax-rotation, the first component contained 6 items and explained $31.86 \%$ of the variance, and the second one 4 items, explaining $19.71 \%$ of the variance. The content of the items suggested that the components reflected'negative attitude towards respecting of speed limits' and the'positive attitude towards respecting the speed limits', respectively. The correlation between the two components was -.136 .

\subsubsection{Social norm}

A Principal Component analysis on the 9 items measuring social norm resulted in a 2 -factor solution explaining $52.54 \%$ of the variance after applying the eigenvalue criterium. The first component included 5 items accounting for $30.48 \%$ of the total variance, and the second component 4 items accounting for $26.21 \%$ of the variance. Items with a high loading on the first component referred mostly to an explicit (subjective) social norm that was positive with regard to safe speed behaviour (e.g., "Most of the people of my circle of friends or acquaintances think that one should respect the speed limits"), while the items of the second component referred to implicit (normative or personal) norms that were negative with regard to safe speed behaviour (e.g. "Drivers who keep to the speed limits are exceptions"). Consequently, the components were named'explicit social norm' and'implicit social norm' respectively. The correlation between the two components was -.282 .

\subsubsection{Perceived behavioural control}

The principal component analysis on the 6 items assessing perceived behavioural control regarding speed behaviour resulted in a 2 -component solution which explained $57.49 \%$ of the total variance. After a Promax-rotation, 4 items load on the first component, which accounted for $37.46 \%$ of the variance, and the remaining two items on the second, which explained $27.56 \%$ of the total variance. The item content revealed that the first component referred to elements that are within one's own control (e.g., "If I choose to keep to the speed limits, I can do so"), while the second component focused on external control (e.g., "In contemporary traffic one does not decide whether or not to keep to the speed limit, but one must adjust to others"). The scales were subsequently labelled as 'perceived internal control' and'perceived external control'. The correlation between the two components was -.361 . The factor loadings of all items are given in Table 1.

\subsection{Internal consistency}

Internal consistency coefficients ranged from .51 to .81 (see Table 2). Taking into account that Cronbach's alpha is very sensitive to a low number of items, these values suggest that the obtained scales are reasonably 
Table 1

Component loadings of the questionnaire measuring cognitive determinants of speeding

\begin{tabular}{|c|c|c|c|c|c|c|c|c|c|}
\hline & & 1 & 2 & 3 & 4 & 5 & 6 & 7 & 8 \\
\hline \multicolumn{10}{|c|}{ Attitude towards fast driving } \\
\hline 1 & Driving fast helps you to arrive at your destination more quickly & .680 & .019 & - & - & - & - & - & - \\
\hline 2 & Driving fast is inconvenient for other drivers & -.004 & .727 & - & - & - & - & - & - \\
\hline 3 & Driving fast makes you feel independent and free & .795 & .005 & - & - & - & - & - & - \\
\hline 4 & Driving fast gives you self-confidence & .725 & .041 & - & - & - & - & - & - \\
\hline 5 & Driving fast is stressful & -.201 & .450 & - & - & - & - & - & - \\
\hline 6 & Driving fast enables you better to follow the traffic flow & .427 & -.277 & - & - & - & - & - & - \\
\hline 7 & Driving fast gives you a feeling of control of your car & .543 & -.052 & - & - & - & - & - & - \\
\hline 8 & Driving fast is expensive & -.046 & .674 & - & - & - & - & - & - \\
\hline 9 & Driving fast increases the risk of severe accidents & .073 & .783 & - & - & - & - & - & - \\
\hline 10 & Driving fast damages the environment & .102 & .847 & - & - & - & - & - & - \\
\hline 11 & Driving fast makes you win time & .712 & .013 & - & - & - & - & - & - \\
\hline 12 & Driving fast is exciting & .540 & .062 & - & - & - & - & - & - \\
\hline \multicolumn{10}{|c|}{ Attitude towards respecting speed limits } \\
\hline 1 & $\begin{array}{l}\text { Respecting the speed limit makes you need more time to reach } \\
\text { your destination }\end{array}$ & - & - & .781 & -.133 & - & - & - & - \\
\hline 2 & Respecting the speed limit is inconvenient for other drivers & - & - & .679 & -.080 & - & - & - & - \\
\hline 3 & $\begin{array}{l}\text { Respecting the speed limit reduces the chance to get involved in } \\
\text { an accident }\end{array}$ & - & - & -.025 & .688 & - & - & - & - \\
\hline 4 & Respecting the speed limit makes you drive more relaxed & - & - & -.094 & .748 & - & - & - & - \\
\hline 5 & Respecting the speed limit is monotonous & - & - & .719 & .032 & - & - & - & - \\
\hline 7 & $\begin{array}{l}\text { Respecting the speed limit gives you a feeling of control of your } \\
\text { car }\end{array}$ & - & - & .080 & .736 & - & - & - & - \\
\hline 8 & Respecting the speed limit makes you lose time & - & - & .874 & .141 & - & - & - & - \\
\hline 9 & $\begin{array}{l}\text { Respecting the speed limit allows you better to take unforeseen } \\
\text { traffic situations into account }\end{array}$ & - & - & .035 & .534 & - & - & - & - \\
\hline 11 & Respecting the speed limit restricts your freedom & - & - & .571 & -.050 & - & - & - & - \\
\hline \multirow[t]{2}{*}{12} & $\begin{array}{l}\text { Respecting the speed limit makes it less easy to follow the traffic } \\
\text { flow }\end{array}$ & - & - & .674 & .076 & - & - & - & - \\
\hline & Speeding behaviour & 1 & 2 & 3 & 4 & 5 & 6 & 7 & 8 \\
\hline \multicolumn{10}{|c|}{ Social norm } \\
\hline & Most drivers in Flanders do not respect the speed limit & - & - & - & - & .041 & .774 & - & - \\
\hline & $\begin{array}{l}\text { Most of my friends and acquaintances think that speed limits } \\
\text { should be respected }\end{array}$ & - & - & - & - & .788 & -.007 & - & - \\
\hline 3 & People who respect the speed limits make fools of themselves & - & - & - & - & .154 & .535 & - & - \\
\hline 4 & Occasionally driving faster than the speed limit is acceptable & - & - & - & - & .504 & -.191 & - & - \\
\hline 5 & Drivers who respect the speed limits are exceptions & - & - & - & - & -.049 & .822 & - & - \\
\hline 6 & $\begin{array}{l}\text { Most of my friends and acquaintances do not respect the speed } \\
\text { limits }\end{array}$ & - & - & - & - & -.136 & .682 & - & - \\
\hline 7 & Drivers who respect the speed limits are an example for others & - & - & - & - & .790 & .283 & - & - \\
\hline 8 & My partner thinks that I should respect the speed limits & - & - & - & - & .671 & .021 & - & - \\
\hline 9 & $\begin{array}{l}\text { Most Flemish people find it advisable that drivers respect the } \\
\text { speed limits }\end{array}$ & - & - & - & - & .761 & -.136 & - & - \\
\hline 10 & $\begin{array}{l}\text { My children think that I should respect the speed limits (If you } \\
\text { do not have children you may skip this question) }\end{array}$ & - & - & - & - & .041 & .774 & - & - \\
\hline \multicolumn{10}{|c|}{ Perceived behavioural control } \\
\hline & If I choose to respect the speed limits, I can do it. & - & - & - & - & - & - & .735 & -.079 \\
\hline & $\begin{array}{l}\text { In contemporary traffic one does not decide whether or not to } \\
\text { keep to the speed limit, but one must adjust to others }\end{array}$ & - & - & - & - & - & - & .133 & .904 \\
\hline 3 & I can respect the speed limit even when other drivers are speeding & - & - & - & - & - & - & .651 & -.174 \\
\hline 4 & $\begin{array}{l}\text { Whether or not I can respect the speed limit depends on the } \\
\text { circumstances, not on me }\end{array}$ & - & - & - & - & - & - & -.150 & .708 \\
\hline 5 & I have often tried to reduce my speed but I cannot & - & - & - & - & - & - & .812 & .165 \\
\hline & $\begin{array}{l}\text { Driving safely is a question of personality: those who choose to } \\
\text { do so will manage }\end{array}$ & - & - & - & - & - & - & .633 & .029 \\
\hline
\end{tabular}

Note: 1 = positive attitude 'driving fast', $2=$ negative attitude 'driving fast', $3=$ negative attitude 'respecting speed limits', $4=$ positive attitude 'respecting speed limits', $5=$ explicit norm, $6=$ implicit norm, $7=$ perceived internal control, $8=$ perceived external control. 
Table 2

Number of items, internal consistencies and inter-correlations for the scales of the questionnaire measuring cognitive determinants of speeding ${ }^{1}$

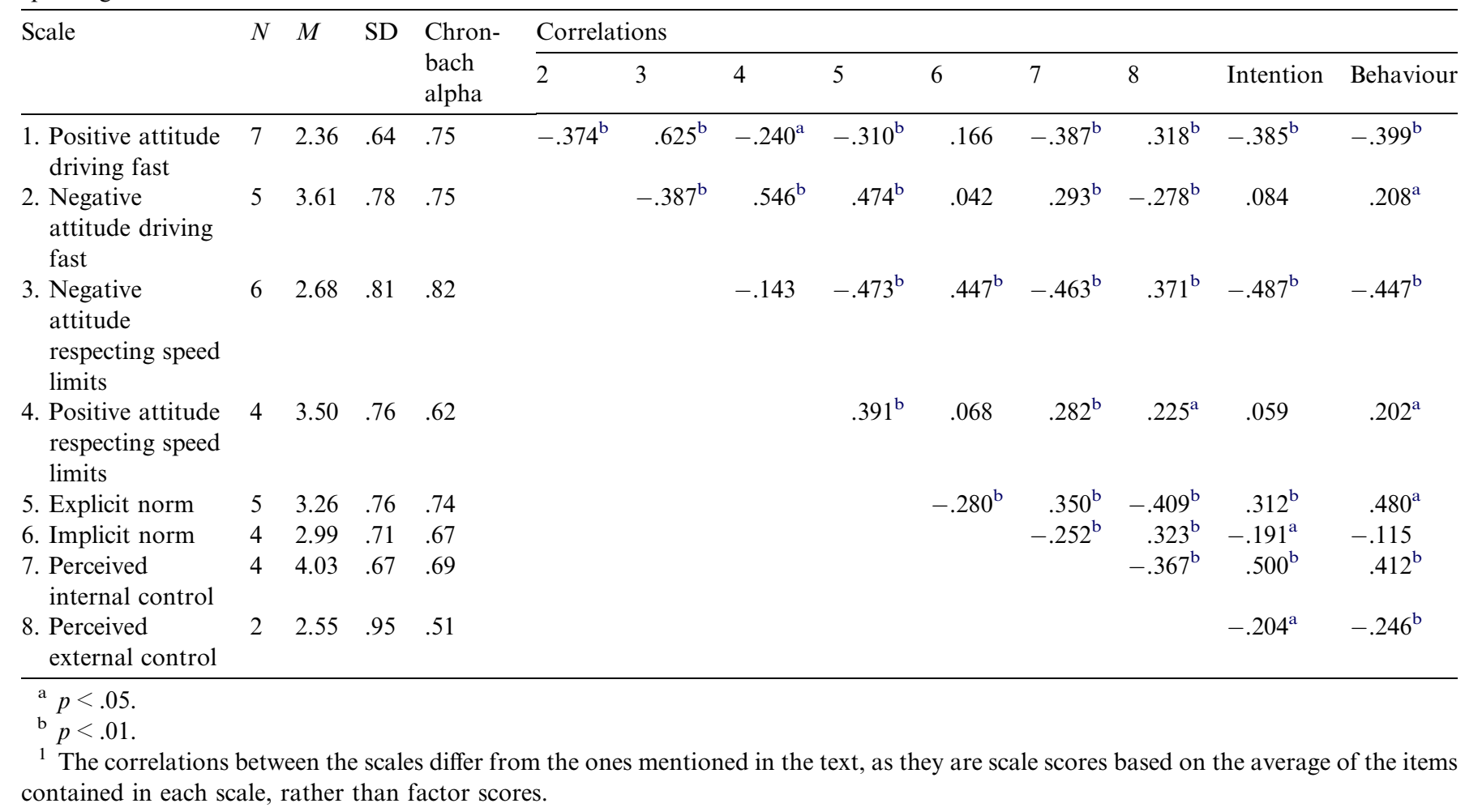

homogenous. Table 2 also lists the Pearson correlations between the scales. These intercorrelations are rather moderate. With the exception of 4 out of 28 ( 3 of which from the 'implicit norm' scale), all intercorrelations reached statistical significance at the .05 level or less.

\subsection{Predictive validity}

Multiple regression analyses revealed that the 8 scales representing the participants' attitude, social norm and perceived behavioural control to a large extent predict the intention to keep to the speed limits $\left(R^{2}=.360\right.$; $F(8,89)=6.255, p<.001$ ) (Table 3 ). The largest contribution to the prediction of intention was provided by the scales 'explicit social norm' $(\beta=.393, p=.001)$ and 'negative attitude towards respecting the speed limits' ( $\beta=-.278, p=.043)$. Self-reported speeding behaviour could significantly be predicted by intention and perceived behavioural control $\left(R^{2}=.580, F(3,107)=49,267, p<.001\right)$, with the largest contribution noted for intention $(\beta=.638, p<.001)$ and perceived internal control $(\beta=.254, p=.001)$, respectively. Perceived external control did not contribute to the prediction $(\beta=-.039)$.

In contrast, multiple regression analyses towards the three variables measuring actual behaviour showed no significant prediction on the basis of intention and perceived internal or external control $\left(R^{2}=.085, F(3\right.$, $21)=.647, p=.593$ for average speed; $R^{2}=.327, F(3,15)=2.434, p=.105$ for number of violations; and $R^{2}=.216, F(3,18)=1.657, p=.212$ for duration of violations, respectively), although the beta coefficients are considerable, especially for perceived internal control (.769 for number of violations, .453 for duration of violations and -.361 for average speed) and intention (-.455 for number of violations and -.532 for duration of violations), and the percentage of variance explained by the TPB dimensions is quite high for number and duration of violations. A direct regression of the eight cognitive variables towards the behaviour measures revealed a prediction at the $10 \%$ significance level for average speed $\left(R^{2}=.575 ; F(8,14)=2.365 p=.076\right)$, which must almost completely be attributed to 'negative attitude towards respecting speed limits' $(\beta=.903$, $p=.009)$. No significant prediction was found for the number of speed violations $\left(R^{2}=.662 ; F(8\right.$, $8)=1.960 p=.180)$ and the duration of the violations $\left(R^{2}=.407 ; F(8,11)=.945 p=.519\right)$, although again the percentage of variance explained is high. 
Table 3

Multiple regressions of the behavioural determinants towards intention, self-reported behaviour and objective behaviour

\begin{tabular}{|c|c|c|c|c|}
\hline & $R^{2}$ & $\beta$ & $t$ & $p$ \\
\hline Intention to respect the speed limits & .360 & & & \\
\hline Positive attitude driving fast & & -.108 & -.939 & .350 \\
\hline Negative attitude driving fast & & -.211 & -1.778 & .079 \\
\hline Negative attitude respecting speed limits & & -.278 & -2.054 & .043 \\
\hline Positive attitude respecting speed limits & & .052 & .487 & .628 \\
\hline Explicit norm & & .393 & 3.465 & .001 \\
\hline Implicit norm & & .180 & 1.652 & .102 \\
\hline Perceived internal control & & .162 & 1.613 & .110 \\
\hline Perceived external control & & .022 & .208 & .836 \\
\hline Self-reported observing of speed limits & .580 & & & \\
\hline Intention & & .638 & 9.255 & $<.001$ \\
\hline Perceived internal control & & .254 & 3.509 & .001 \\
\hline Perceived external control & & .052 & .761 & .448 \\
\hline \multicolumn{5}{|l|}{ Objective speeding behaviour } \\
\hline Average speed & .085 & & & \\
\hline Intention & & .198 & .721 & .479 \\
\hline Perceived internal control & & -.361 & -1.307 & .205 \\
\hline Perceived external control & & -.157 & -.732 & .472 \\
\hline Number of violations & .327 & & & \\
\hline Intention & & -.455 & -1.572 & .137 \\
\hline Perceived internal control & & .769 & 2.633 & .019 \\
\hline Perceived external control & & -.018 & -.082 & .936 \\
\hline Duration of violations & .216 & & & \\
\hline Intention & & -.532 & -2.040 & .056 \\
\hline Perceived internal control & & .453 & 1.730 & .101 \\
\hline Perceived external control & & -.023 & -.108 & .915 \\
\hline
\end{tabular}

\subsection{Discriminative validity}

The results of a MANOVA showed no significant multivariate difference between males and females on the combined attitude, social norm and perceived behavioural control scales (Wilks' lambda $=.871, F=1.661$, $\mathrm{d} f=90, p=.119)$. However, univariate $F$-tests for the scales separately showed that female drivers scored significantly higher than males on the'perceived internal control' scale $(F(1,97)=5.425, p=.022)$. This suggests that women believe more than men that they can determine their own speed in traffic. On all the other scales, female drivers scored somewhat lower than males but these differences were not significant (Table 4).

Table 4

Gender differences on the scales of the questionnaire measuring determinants of speeding

\begin{tabular}{|c|c|c|c|c|c|c|}
\hline & \multicolumn{4}{|c|}{ Means and standard deviations } & \multirow[t]{3}{*}{$F$} & \multirow[t]{3}{*}{$p$} \\
\hline & \multicolumn{2}{|l|}{ Male } & \multicolumn{2}{|c|}{ Female } & & \\
\hline & $M$ & SD & $M$ & SD & & \\
\hline Positive attitude driving fast & 2.37 & 0.61 & 2.28 & 0.65 & 0.402 & .528 \\
\hline Negative attitude driving fast & 3.70 & 0.75 & 3.40 & 0.80 & 3.125 & .080 \\
\hline Negative attitude respecting speed limits & 2.69 & 0.81 & 2.47 & 0.82 & 1.355 & .247 \\
\hline Positive attitude respecting speed limits & 3.55 & 0.73 & 3.41 & 0.88 & 0.619 & .433 \\
\hline Explicit norm & 3.29 & 0.76 & 3.19 & 0.76 & 0.338 & .563 \\
\hline Implicit norm & 3.03 & 0.74 & 2.87 & 0.65 & 0.999 & .320 \\
\hline Perceived internal control & 3.94 & 0.65 & 4.28 & 0.65 & 5.425 & .022 \\
\hline Perceived external control & 2.60 & 0.95 & 2.40 & 0.95 & 0.836 & .363 \\
\hline
\end{tabular}




\section{Discussion}

The purpose of this study was to develop a valid, reliable and user friendly questionnaire to measure the determinants of speeding behaviour, based on the theory of planned behaviour. According to this model, volitional behaviour is determined by intentions to perform that behaviour and by perceived control of the behaviour, while intentions are influenced by attitudes towards the behaviour, subjective norms and perceived behavioural control.

Starting from this model, the concept validation approach was followed to construct the questionnaire. This approach involves three steps: the explicit definition of the concepts of interest based on a theoretical model; the development and internal (or construct) validation of an instrument to assess these concepts; and the external validation of the instrument, aimed at establishing its predictive validity and/or its relationship to other tools (Wiggins, 1973). In accordance with this approach, a provisional questionnaire was developed reflecting the TPB dimensions as applied to speeding behaviour, and completed by a sample of 116 civil servants. Although a principle component analysis on the entire set of items could not reproduce the theoretical dimensions of the TPB, separate principal component analyses on the items measuring attitudes, social norms and perceived control resulted in interpretable two component solutions for each determinant. The two components that were found for each theoretical dimension correspond with findings reported elsewhere. Specifically, the differentiation between explicit and implicit social norms reflects the difference between subjective versus normative and personal norms (De Pelsmacker \& Janssens, 2007), the former referring to the social pressure by significant others, and the latter to the opinions or norms of others as inferred from their behaviour, and to the moral values people have as to what they should or should not do. The differentiation between perceived internal and external control reflects the difference between self-efficacy and perceived behavioural control, as mentioned by Armitage and Conner (1999). While these terms are often though of as interchangeable, they are in fact different constructs which both may contribute to the prediction of intentions and behaviours. Thus, the results of the principal component analyses in this study confirm that implicit and explicit social norms, as well as perceived internal and external control, should not be seen as single dimensions, but as separate determinants of intentions and behaviour.

The difference between positive and negative attitudes towards speeding and towards observing the speed limits, on the other hand, may be the result of acquiescence as a response tendency in the sample. Acquiescence refers to the systematic preference to agree with the statement, irrespective of its content, either because of unfamiliarity with expressing a personal point of view on a questionnaire, or a low motivation to cooperate in questionnaire research. It makes positive correlations between items more positive and negative correlations less negative, which may result in bipolar components being separated in two unipolar ones, as was the case for the attitude scales. However, as the correlations between these unipolar scales are not very high (i.e., -.37 and -.14, respectively), they do not show much overlap and can be regarded as relatively independent, which attests to their stability. Moreover, the high percentage of variance explained by the two components that were found for each determinant, as well as the high component loadings and the satisfactory levels of internal consistency, all attest to the construct validity of the scales that were based on these component analyses.

The discriminative power of the questionnaire was investigated by looking at the gender disparity in the determinants of driving behaviour. These have been well documented in traffic research (Bergdahl \& Norris, 2002; Laapotti, Keskinen, Hatakka, \& Katila, 2001). Our finding that female drivers scored significantly higher than males on the perceived internal control scale is consistent with these findings, in the sense that women have a more realistic appraisal of the relationship between their behaviour and the probability of an accident. De Joy (1992) established that "males and females [hold] similar perceptions concerning the frequency of accident likelihood of risky behaviours, but males perceive their own behaviours as generally less likely to result in accidents' (p. 237). The fact that women have a more accurate appraisal of their driving would concur with the finding that they believe that they can determine their own speed in traffic. On the other hand, female drivers in our sample did not have a more positive attitude towards traffic regulations and safe driving than males, as has been reported in other studies (e.g., Parker et al., 1992). This may be due to the fact that for the entire sample, both for female and male drivers, the overall attitude towards safe driving and observing the traffic regulations was rather positive. The latter may related to the relatively high education 
level of the participants. As such, their average scores the scales of the questionnaire should not be regarded as representative for the population at large.

In terms of predictive validity of the questionnaire, multiple regression analyses indicated that, as assumed by the TPB, the attitude, subjective norm and perceived behavioural control scales significantly contributed to the prediction of the intention to keep to speed limits. The combined determinants explained $36 \%$ of the variance in intention, which is in the same range as reported for other behaviours. In their meta-analysis of the application of the TPB on a variety of health related problems, Armitage and Conner (2001) found that attitude, subjective norm and perceived behavioral control in combination accounted for a frequency weighted average of $39 \%$ of the variance in intention across 154 applications. Further, our findings indicate that explicit social norm, along with negative attitude towards respecting the speed limits, were the determinants that contributed most strongly to intentions. This seems to contradict the belief that behaviour in traffic is more strongly determined by normative and descriptive (implicit) norms than by subjective (explicit) norms (De Pelsmacker \& Janssens, 2007). However, Haglund and Aberg (2000) also found that the external pressure to keep up with other drivers was a significant predictor of speeding intentions.

Further adding to the predictive validity of the questionnaire, intentions and perceived (internal) control significantly predicted the self-reported speeding behaviour, as hypothesized by the TPB. With $77 \%$ of the variance in self-reported behaviour explained by the combination of intentions and perceived internal and external control, this prediction is in fact much higher than in most other studies, where intentions and perceived behavioral control on average explain only $27 \%$ of the variance in behavior (Armitage \& Conner, 2001). It should be noted, however, that the latter figure was obtained from a meta-analysis of studies where the relationship between the TPB-dimensions and self-reported behaviour was assessed prospectively, i.e. TPB measured at time 1 and behaviour at time 2, whereas in our study the TPB and self-reported behaviour measures were included in the same questionnaire and measured simultaneously. As such, we actually measured past behaviour, and not subsequent behaviour. This may have caused a consistency bias which artificially inflated the relationships between cognitions and behaviour, which would explain the very high percentage of variance in self-reported behaviour accounted for by the model.

While the relationship with self-reported behaviour, due to the simultaneous measurement, may have given an inaccurate estimation of the predictive validity of the questionnaire, a better estimate of the predictive validity is achieved by looking at the relationship with actual behaviour, measured at a later point in time. Although the multiple regressions of the TPB dimensions towards the three variables measuring speeding behaviour did not reveal a statistically significant relationship, the TPB dimensions do account for a considerable part of the variation in observed behaviour, especially with regard to the number and duration of speeding violations, where moderate to large effect sizes are observed ( $R^{2}$ of .22 and .33). Moreover, the correlations between the TPB predictors and behavioural measures are highly significant. The fact that despite the fairly large effect sizes no significance was obtained may be due to the lack of power, with only 55 subjects participating in the behavioural monitoring part of the study. The latter is supported by the fact that two recent studies investigating the relationship between speeding intentions and speeding behaviour measured objectively via a driving stimulater or on-road driving behaviour (Connor et al., 2007; Elliott, Armitage, \& Baughan, 2007) reported similar effect sizes, but reached statistical significance as they involved larger samples (303 and 150 subjects, respectively). On the other hand, the relatively weaker relationship between the TPB and average speed could be explained by the principle of correspondence (Fishbein \& Ajzen, 1975), in the sense that measures of average speed are less compatible with TPB measures than the number and duration of speed violations.

So, while confirming the finding of other studies that the predictive validity of the TPB drops considerably if objective rather than subjective indicators of performance are used (Armitage \& Conner, 1999; Rothengatter, 2002; Victoir et al., 2005), our findings support the finding of the above mentioned studies by showing that the dimensions of the TPB to a considerable extent predict actual, objective driving behaviour. This is not to say that self-reported behaviour is without any value: Objective driving data such as the ones collected via the on-board CPU in this study are not always easy to obtain in a cost effective way. Self-reports on safe driving can thus be a reasonable approximation of the actual performance, given their significant correlation with actual behaviour. However, as this study demonstrates, to predict or influence actual rather than self-reported behaviour, the cognitive determinants of safe driving as identified by the TPB need to be complemented by 
other factors, including less "conscious" cognitive factors such as personal identity and habit formation, as well as external factors, such as cues to action, reinforcers, or the design of the roads.

\section{References}

Aeron-Thomas, A. S., \& Hess, S. (2005). Red-light cameras for the prevention of road traffic crashes. Cochrane Database Systematic Review, 18(2), CD003862.

Aberg, L. (1993). Drinking and driving: Intentions, attitudes, and social norms of Swedish male drivers. Accident Analysis and Prevention, 25, 289-296.

Ajzen, I. (1991). The theory of planned behaviour. Organizational Behaviour and Human Decision Processes, 50, $179-211$.

Ajzen, I., \& Madden, T. J. (1986). Prediction of goal directed behaviour: Attitudes, intentions and perceived behavioural control. Journal of Experimental Social Psychology, 22, 453-474.

Armitage, C. J., \& Conner, M. (1999). The theory of planned behaviour: Assessment of predictive validity and perceived control. British Journal of Social Psychology, 38, 35-54.

Armitage, C. J., \& Conner, M. (2001). Efficacy of the theory of planned behaviour: A meta-analytic review. British Journal of Social Psychology, 40, 471-499.

Armitage, C. J., Norman, P., \& Conner, M. (2002). Can the theory of planned behaviour mediate the effects of age, gender and multidimensional health locus of control? British Journal of Health Psychology, 7, 299-316.

Bergdahl, J., \& Norris, M. R. (2002). Sex differences in single vehicle fatal crashes: A research note. The Social Science Journal, 39, 287-293.

Budd, R. J., North, D., \& Spencer, C. (1984). Understanding seat belt use: a test of Bentler and Speckart's extension of the Theory of Reasoned Action. European Journal of Social Psychology, 14, 69-78.

Bunn, F., Collier, T., Frost, C., Ker, K., Roberts, I., \& Wentz, R. (2003). Traffic calming for the prevention of road traffic injuries: Systematic review and meta-analysis. Injury Prevention, 9, 200-204.

Connor, M., Lawton, R., Parker, D., Chorlton, K., Manstead, A. S. R., \& Stradling, S. (2007). Application of the theory of planned behaviour to the prediction of objectively assessed breaking of posted speed limits. British Journal of Psychology, 98, 429-453.

De Brabander, B., Nuyts, E., \& Vereeck, L. (2005). Road safety effects of roundabouts in flanders. Journal of Safety Research, 36, $289-296$.

DePelsmacker, P., \& Janssens, W. (2007). The effect of norms, attitudes and habits on speeding behavior: Scale development and model building and estimation. Accident Analysis and Prevention, 39(1), 6-15.

De Joy, D. M. (1992). An examination of gender differences in traffic accident risk perception. Accident Analysis and Prevention, 24, 237-246.

Elliott, M. A., Armitage, C. J., \& Baughan, C. J. (2003). Drivers compliance with speed limits: An application of the theory of planned behaviour. Journal of Applied Psychology, 88, 964-972.

Elliott, M. A., Armitage, C. J., \& Baughan, C. J. (2007). Using the theory of planned behaviour to predict observed driving behaviour. British Journal of Social Psychology, 46, 90-96.

European Commission. (2003). Road Infrastructure Safety Management. Report of the Working Groep on Infrastructure Safety. Brussel: European Commission, DG Transport and Energy. $<$ http://europa.eu.int/comm/transport/road/roadsafety/roadinfra/ reports_en.htm>.

Evans, D., \& Norman, P. (1998). Understanding pedestrians' road crossing decisions: An application of the Theory of Planned Behaviour. Health Education Research, 13, 481-489.

Fishbein, M., \& Ajzen, I. (1975). Belief, attitude, intention and behavior: An introduction to theory and research. Reading, MA: AddisonWesley.

Garvill, J., Marell, A., \& Westin, K. (2003). Factors influencing drivers' decision to install an electronic speed checker in the car. Transportation Research Part C, 7, 131-147.

Gielen, A. C., Eriksen, M. P., Daltroy, L. H., \& Rost, K. (1984). Factors associated with the use of child restraint devices. Health Education Quarterly, 11, 195-206.

Gielen, A. C., \& Sleet, D. (2003). Application of behavior-change theories and methods to injury prevention. Epidemiologic Reviews, 25, 65-76.

Godin, G., \& Kok, G. (1996). The theory of planned behaviour: A review of its applications to health related behaviours. American Journal of Health Promotion, 11, 87-98.

Haglund, M., \& Aberg, L. (2000). Speed choice in relation to speed limit and influences from other drivers. Transportation Research Part F, 3, 39-51.

Harloff, H. J. (1994). Die Bedeutung des Verkehrs für Mensch und Gesellschaft. In A. Flade (Ed.), Mobiliteitsvderhalten - Bedingungen en Veränderungsmöglichkeiten aus Umweltpsychologischer Sicht (pp. 25-36). Weinheim: Psychologie Verlags Union.

Hatakka, M., Keskinen, E., Gregersen, N. P., Glad, A., \& Hernetkoski, K. (2002). From control of the vehicle to personal self-control; broadening the perspectives to driver education. Transportation Research Part F, 5, 201-215.

Laapotti, S., Keskinen, E., Hatakka, M., \& Katila, A. (2001). Novice drivers-accidents and violations - A failure on higher or lower hierarchical levels of driving behaviour. Accident Analysis and Prevention, 33, 759-769.

Mäkinen, T., Zaidel, D. M., Andersson, G., Biecheler-Fretel, M. B., Christ, R., Cauzard, J. P., et al. (2003). Traffic enforcement in Europe: Effects, measures, needs and future. Brussels: European Commission. 
Marcil, I., Bergeron, J., \& Audet, T. (2001). Motivational factors underlying the intention to drink and drive in young male drivers. Journal of Safety Research, 32, 363-376.

Moyano Diaz, E. (2002). Theory of planned behaviour and pedestrians' intentions to violate traffic regulations. Transportation Research Part F, 5, 169-175.

Newnam, S., Watson, B., \& Murray, W. (2004). Factors predicting intentions to speed in a work and personal vehicle. Transportation Research Part F, 7, 287-300.

Parker, D., Manstead, A. S. R., Stradling, S. G., Reason, J. T., \& Baxter, J. S. (1992). Intention to commit driving violations: An application of the theory of planned behaviour. Journal of Applied Psychology, 77, 94-101.

Parker, D., Manstead, A. S. R., \& Stradling, S. G. (1995). Extending the theory of planned behaviour: The role of personal norm. British Journal of Social Psychology, 34, 127-137.

Parker, D., Stradling, S. G., \& Manstead, A. S. R. (1996). Modifying beliefs and attitudes to exceeding the speed limit: An intervention study based on the theory of planned behaviour. Journal of Applied Social Psychology, 26, 1-19.

Peden, M. M., Krug, E., Mohan, D., et al. (2001). Five-year WHO strategy on road traffic injury prevention. Geneva: World Health Organization, Ref: WHO/NMH/VIP/01.03.

Pilkington, P., \& Kinra, S. (2005). Effectiveness of speed cameras in preventing road traffic collisions and related casualties: Systematic review. British Medical Journal, 330(7487), 331-334.

Quine, L., Rutter, D. R., \& Arnold, L. (2001). Persuading school-age cyclists to use safety helmets: Effectiveness of an intervention based on the theory of planned behaviour. British Journal of Health Psychology, 6, 327-345.

Rothengatter, T. (2002). Drivers illusions-no more risk. Transportation Research Part F, 5, 249-258.

Stead, M., Tagg, S., MacKintosh, A. M., \& Eadie, D. (2005). Development and evaluation of a mass media theory of planned behaviour intervention to reduce speeding. Health Education Research, 20(1), 36-50.

Thuen, F., \& Rise, J. (1994). Young adolescents' intention to use seat belts: The role of attitudinal and normative beliefs. Health Education Research, 9, 215-223.

Trifiletti, L. B., Gielen, A. C., Sleet, D. A., \& Hopkins, K. (2005). Behavioral and social sciences theories and models: Are they used in inintentional injury prevention research? Health Education Research, 20(3), 298-307.

Van den Putte, B., \& Hoogstraten, J. (1997). Applying structural equation modeling in the context of the theory of reasoned action: Some problems and resolutions. Structural Equation Modeling, 4, 320-337.

Victoir, A., Eertmans, A., Van den Bergh, O., \& Van den Broucke, S. (2005). Learning to drive safely: Social-cognitive responses are predictive of performance rated by novice drivers and their instructors. Transportation Research Part F, 8, 59-74.

Wiggins, J. S. (1973). Personality and prediction. Reading: Addison Wesley.

Wittenbracker, J., Gibbs, B., \& Kahle, L. R. (1983). Seat belt attitudes, habits and behaviors: An adaptive amendment to the Fishbein model. Journal of Applied Social Psychology, 13, 406-421.

World Health Organization. (2000). Transport, environment and health. WHO Regional Publications, European Series, No. 89. 